\title{
Managing flexworkers: holding on and letting go
}

\author{
Julia Richardson \\ Atkinson Faculty, York University, Toronto, Canada
}

\begin{abstract}
Purpose - The purpose of this paper is to explore what it means to be a manager in the context of working from home, or "flexworking", as an increasingly common work practice.

Design/methodology/approach - The paper is located within an interpretive interactionist perspective, drawing on interviews with managers who took part in a larger qualitative study of employees who work from home two or more days a week in the Canadian subsidiary of a high-tech MNC. Template analysis identified themes which are most salient in managers" experiences of managing these "flexworkers".

Findings - The findings point to several key themes in interviewees' experiences of managing flexworkers: maintaining a balance between providing autonomy alongside appropriate levels of cohesion between themselves and employees and between employees; the increasing importance of trust and the centrality of interpersonal relationships and interactions.

Research limitations/implications - A limitation is a relatively small sample size (27) in the Canadian hi-tech industry. Also, the findings may not be applicable to other industries or to managers in other countries. The paper's location within an interpretive interactionist framework accords primary focus to individual action rather than structural forces.

Practical implications - Contemporary management development initiatives should balance communication and support, while avoiding micromanagement. They should also develop managers' ability to ensure that social bonds are maintained but do not undermine the principles of flexwork.

Originality/value - There is a paucity of qualitative research on flexworking in Canada. Moreover, the paper contributes a theoretical understanding of this work arrangement, whereas previous research has been primarily descriptive.
\end{abstract}

Keywords Trust, Qualitative research, Canada

Paper type Research paper

Introduction

Changes in organizational forms have meant increasing diversity in work processes and practices, including a growing trend towards allowing employees to work from home (i.e. flexwork) one or more days a week or, in some cases, on a permanent basis. These changes are closely connected to technological innovation and its impact on how work is done, where it is done and by who (Tietze, 2002). However, as this special issue suggests, changes in organizational forms and practices have a direct impact on management practices and what it means to be a manager. In the context of flexworking, for example, relationships between managers and employees are no longer based on daily "face-to-face" interaction but on a more physically distant and perhaps "virtual and fleeting acquaintance". Moreover, the "social bonds" that emerge from the physical presence of employees and their managers become increasingly tenuous. Indeed, research on teleworkers (as a broader category within which flexwork can be located) has suggested that they may feel isolated from their colleagues and are concerned that it may have a negative impact on their career advancement/visibility (Crandall and Gao, 2005; Harris, 2003). 
Drawing on a qualitative study of 27 managers/team leaders in a large multi-national company (MNC) in Canada, this paper explores their individual experiences of managing flexworkers. The term "flexwork" is adopted here because it was used by this organization to describe this particular work practice. While the organization distinguished flexworkers from teleworkers, who they understood as employees working from home on a permanent basis, the boundaries between the two are blurred. Thus, for example, neither the teleworkers nor many of the flexworkers in this organization had a permanent office. To that extent, "flexwork" may be understood as one form of telework. Focusing on Canada as the country in which this study took place, Tremblay (2003) suggests that roughly 8 percent of Canadian workers are engaging in some form of telecommuting on a full time or part time basis. Nonetheless, because "research on Canadian teleworkers is particularly scarce" (Schweitzer and Duxbury, 2006, p. 116) the specific dynamics of teleworking in Canada and the implications for contemporary management practices remain a relatively unexplored research territory. Thus, this paper contributes to the current literature on teleworking as a broader category by addressing flexworking in a Canadian business organization.

Bailey and Kurland (2002) suggest that much of the early empirical work on teleworkers focused on individual experiences of teleworking - particularly the advantages and disadvantages of telework. Subsequent literature has tended to converge on who engages in telework, why they do so and the professional and personal outcomes of having done so (e.g. Gainey and Clenney, 2006; Kelliher and Anderson, n.d.; Tietze, 2002; Tietze and Musson, 2003). This paper will build on Harris's study (2003) of what it means to manage a group of employees who are working from home rather than focusing on the more "traditional" subject of individual experiences of working from home. In doing so it also contributes an alternative perspective by "reconnecting" the individual "back" to the organization by explicitly acknowledging that in as much as flexworkers spend some of their time working outside the physical locale of the organization they are still very much a part of organizational dynamics and must, therefore, be managed accordingly. As a further note, Bailey and Kurland suggest that "empirical research to date has been largely unsuccessful in identifying and explaining what happens when people telework" (2002, p. 394). In order to address this explanatory gap, the paper draws on interpretive interactionism as a "lens" through which to theorize the dynamics of managing flexworkers as an inherently social and evolving process. It pays particular attention to interpretive interactionist understandings of experience, interaction, interpretation of meaning and identity construction.

\section{Interpretive interactionism}

Interpretive interactionism is a contemporary version of symbolic interactionism (Denzin, 1989, 1992) which, drawing heavily on Mead, focuses primarily on "the study and imputation of meaning, motive, intention, emotion, and feelings, as these mental and interactive states are experienced and organized by interacting individuals" (Denzin, 1992, p. 129). While it retains many of the original theoretical tenets, interpretive interactionism is best understood as a response to past criticisms of symbolic interactionism particularly the charges of astructural bias. Located in an interpretive ontology (Layder, 1994) and assuming that the social world is an emergent 
process created by individuals, interpretive interactionism offers a useful lens through which to understand what it means to manage flexworkers. Moreover, because reflexive awareness underpins all interpretive interactionist approaches to the self and identity (Denzin, 1992), this paper assumes that managers are able to interpret and account for their experience of managing flexworkers. In other words, that they are able to "stand outside themselves" by taking on the role of the other and viewing themselves from that perspective (Layder, 1994). The paper thereby assumes that managing in a broader context is an on-going, dynamic and evolving process that it is "negotiated" rather than static. While this assumption can be juxtaposed with structural perspectives which view individual behaviour as largely determined by structural and material forces (Burrell and Morgan, 1998), the paper acknowledges that "agency" takes place within the context of such forces but contends that those forces are also created by individual action. In this respect it acknowledges the interplay and mutually constitutive nature of structure, materiality and agency in the specific context of flexworking. Thus, for example, whereas a structuralist analysis would privilege the impact of structural and material forces (such as technology) on managers' experiences of managing flexworkers, this paper views them as mutually constitutive. To that extent it echoes Bridgman and Willmott's contention that rather than determining individual action, structural and material forces, such as technology, are best understood as "simultaneously physical and social" (2006, p. 122).

Interpretive interactionism also assumes that self and identity can only be understood with reference to social interaction (Denzin, 1991). Thus, the paper will contend that manager's and flexworkers identities are "socially bestowed, socially maintained, and socially transformed" (Berger, 1963, p. 98) during the process of management. It will also suggest that a manager's understanding of him/herself is continually evolving through the social experience of managing flexworkers as well as through interaction with others. Put another way, managing flexworkers is a "social location" (Stone, 1962) where managers identify themselves in relation to each other as well as in relation to flexworkers, colleagues, family, friends, etc.

Having introduced the paper's theoretical framework, the study's methodology will be described next, followed by a presentation of the findings and a discussion connecting those findings to some of the key concepts in interpretive interactionist thought.

\section{Methodology}

The findings described in this paper were part of a larger study of a "hi-tech" MNC in Canada. An initiative to increase flexworking throughout the organization had been in place for over a year and was transforming the physical and relational dynamics of the organization. The majority of employees who took part in the study did not have a permanent desk but were required to make use of "hot desks" which were open cubicles to be used when they worked in the head office. This initiative reflected an organizational strategy to reduce real estate costs and enhance overall work practice flexibility.

\section{Data collection}

The larger study explored managers' and employees' individual experiences of flexworking, thus in-depth interviews were the most appropriate method for data 
collection. An agenda of themes with open-ended questions allowed for a broad line of questioning and exploration (Kvale, 1996). The managers described in this paper were encouraged to introduce further themes, if necessary, to elaborate on their experiences of managing flexworkers.

\section{Sampling}

The study is a case study of an organization and the sample is self-selected where an invitation to participate was circulated throughout the head office. In total, 138 employees volunteered to take part in the larger study. Due to time and financial restrictions, 76 interviews were conducted each lasting roughly 45 minutes to one hour. A total of 27 participants had managerial/team leader responsibility for flexworkers and were also flexworkers themselves. The specific demographics of the sample are presented in Figure 1.

\section{Data analysis}

All interviews were transcribed verbatim and analyzed using computer assisted qualitative data analysis software. This software enabled template analysis (King, 2004) and identified themes, which could be connected and arranged into models to provide an overall picture of the findings.

\section{Findings}

A dominant theme in most accounts was that managing flexworkers is fundamentally different to managing office-based employees. This theme echoes Crandall and Gao's argument that "supervising the telecommuting workforce transforms some traditional management practices" (2005, p. 32). Judy, who had extensive experience managing teams of flexworkers as well as being a flexworker herself, pointed out the need for "extra effort":

If they're in the office everyday that thought (of arranging face-to-face interaction) wouldn't enter your mind because you know you're going to see them everyday. So (you) wouldn't need to make arrangements or make a point of saying "I would like you to come into the office"...

so, it takes a lot, a lot more effort (Judy).

Overall, interviewees suggested that the "extra effort" that they associated with managing flexworkers connects to three key themes - communication; allowing for autonomy but avoiding micromanagement (and specifically the ability to maintain a balance between the two) and; the increasing role of trust. Each of these themes will be discussed in the following.

\section{Communication}

All participants specifically described making a concerted effort to maintain appropriate levels of communication with flexworkers. This reflects other studies which have suggested that "the remote working location chips away at the philosophy of close communication and teamwork that so many companies are striving for" (Crandall and Gao, 2005, p. 32). A key concern here was that because they have less physical interaction with their employees it is the managers' responsibility to ensure that they remain accessible to them and vice versa and that their employees remain accessible to each other. From an interpretive interactionist perspective, that they were 

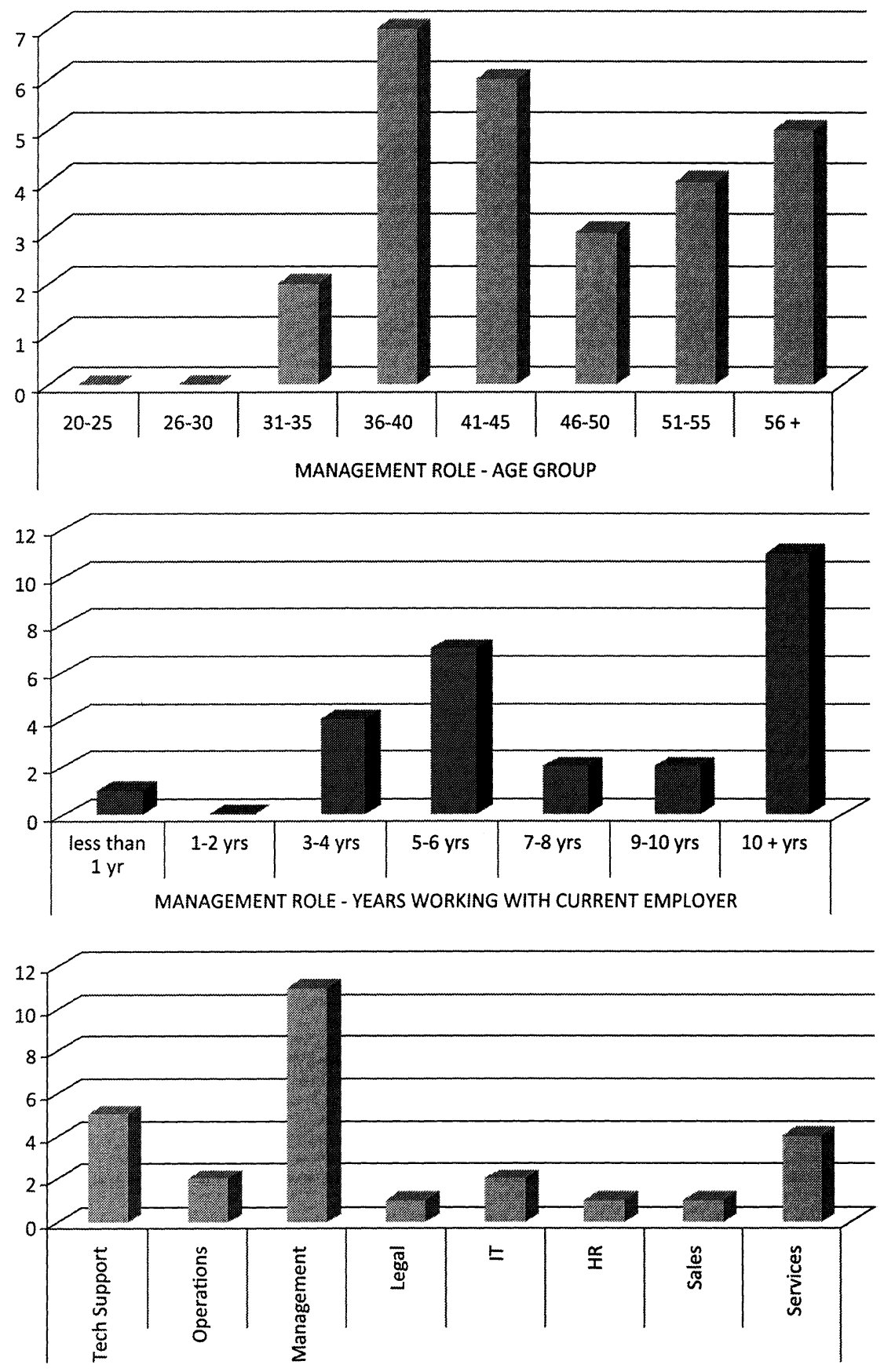

MANAGERIAL ROLE - EMPLOYEE STATUS

Figure 1. 
seeking to "make up" for the lack of physical interaction can be explained by the centrality of interaction in maintaining individual relationships, as explained by Tom:

The human interaction is essential and the challenge is to make that happen so that you don't feel that you are remote from people. You'd have to be reachable at all times. It's nice to be able to know where your team is so you can contact them at all times, if you need to, on an urgent basis. My real function is to support my guys and what they do and to be a "barrier-remover" in their day to day work so it's kind of imperative that they can reach me (Tom).

The overall impression was that in contexts where they have only limited "face to face" contact with employees, such as in flexworking, managers must make a concerted and very deliberate effort to draw on other forms of communication. A key issue here was to avoid what other studies have referred to as "social and professional isolation" (Bailey and Kurland, 2002, p. 390). Yet there was also widespread agreement that "face-to-face" interaction is essential and not easily replaced by other forms of communication, as suggested by Dale, in the following:

As more and more of my team become flex or teleworkers then we have conscious strategies for trying to pull the team together for an event or an informal gathering or a meeting where we ask them to come in for that (Dale).

While flexworking invariably changes the dynamics of relationships between employees and managers the central point here is that the managers who took part in this study are making a specific attempt to avoid those relationships becoming "virtual and fleeting". Thus, though they were not trying to circumvent the organizational initiative for more flexibility, they were deliberately drawing employees back into the office.

In addition to maintaining close relationships with employees, managers also emphasized their role in maintaining/supporting close relationships between employees. A key issue here was "pulling everybody together" (Bella) through organized group breakfast or lunch meetings in addition to spending "face time" (Bella) with individual employees. In this regard these managers clearly reflect interpretive interactionist conceptions of the centrality of (in this case) physical interaction in maintaining and supporting individual relationships. Moreover, in as much as social bonds between peers may have become "less bureaucratic and more informational" the managers who took part in this study were concerned that a lack of physical interaction would have a detrimental impact on knowledge transfer. Thus, the breakfast and lunch meetings were used to maintain social bonds and support knowledge transfer.

\section{Autonomy vs micromanagement: maintaining a balance}

While emphasizing the need to maintain close communication, the majority of interviewees were concerned to avoid perceptions of "micromanagement" - variously described as exerting too much control over individual action, constantly checking on employees and/or otherwise limiting employees' autonomy. They were trying to achieve a balance between maintaining close connections with employees by ensuring appropriate levels of communication yet allowing for autonomy. The accounts also reflected a certainty sensitivity and, at times, uncertainty about how to avoid intervening in employees' personal circumstances. The key point here was, as one 
manager put it "the fine art of holding on as well as letting go" (Paul). Tina, a relatively senior manager, spoke about having to trust her team to "do the right thing" but at the same time not being able to "let go completely". Christopher also spoke about expecting his subordinates to work independently but also supporting them, if necessary:

I expect all of my people to be autonomous. They have to set their own agendas, they have to be self-starters, they have to be able to do their work but they come to me for leverage, for approvals, for my experience. So I'll spend the time supporting them on conference calls (Christopher).

Many managers felt that maintaining a balance between allowing for autonomy yet ensuring that performance levels were achieved was one of the most challenging dimensions of managing flexworkers. Harris (2003) noted a similar theme in her study of a sales team and their line managers during the initial stages of teleworking. She described "a continuing uncertainty about the socially acceptable boundaries of demonstrating concern for individuals which impeded timely responses and the search for solutions to the identified problems" (Harris, 2003, p. 433). Reflecting interpretive interactionist conceptions of the link between social interaction and identity, these managers were trying to avoid behaving in ways which would risk employees seeing them as "micromanagers". In other words, because the identity of "micromanager" is "socially bestowed" they were careful not to behave in ways which might bestow such an identity.

Several managers described a distinct "learning curve" involving a good deal of "trial and error" where, reflecting on their own behaviour, they sought to provide what they felt was the "right balance" between close relationships and individual autonomy. Luigi and Petros, for example, saw managing flexworkers as an essentially evolving skill:

I can say, for the most part, it's been going very well. I have had, I guess, three cases of issues with worker productivity where I've had to go to HR for worker productivity problems and actually monitor their work effort a lot closer than I would have (Luigi).

As a manager, it's difficult to continue acting as a glue to establish the team together (when they start flexworking). Prior to that, it was almost like there were two isles that "this is where all my people sit" and you can easily walk across and find the person there. Now that "walking across" doesn't happen unless you see somebody has come in to work on the hot desks (Petros).

Reflecting the idea of being able to "stand outside oneself", three other managers specifically emphasized being able to engage in what they referred to as "reflective management". The central theme here was being able to "stand back" (Bella) from one's own management style in order to adjust to flexworkers' needs.

The majority of interviewees suggested that managing flexworkers requires some very specific skills, which can only be learned through experience. In this regard we observe how managing flexworkers is an evolving and dynamic process where they were, for the most part, adjusting to the challenges brought on by the flexworking initiative. Indeed, even the most experienced interviewees described their management practices as continually evolving rather than static. 
The evolutionary nature of managing in this organization was also connected to the fact that although external sales had a long tradition of flexworking it was a relatively new practice for employees in other departments. Thus in addition to managing their own employees these managers had to manage in a context where other employees who they might depend on or be connected to were also flexworking. This organization can, therefore, be best understood as an "emergent work environment" where managers must adapt not only to the changing work practices of their own employees but also to changes in other parts of the organization.

\section{Trust}

Continuing with the theme of maintaining a balance between establishing close relationships with employees but avoiding micromanagement, many managers were concerned that micromanagement runs the risk of employees feeling that they are not trusted. This concern was, indeed, well founded because in the larger study non-managerial interviewees expressed strong views about micromanagement, which they saw as signaling a lack of trust. This finding also reflects interpretive interactionist conceptions of the connection between interaction and identity. In particular it suggests that their perceptions of how they were viewed by their managers were directly informed by how their managers behaved towards them. The majority of interviewees suggested that trust was more important in relationships between managers and flexworkers than between managers and office-based employees. This finding echoes other studies, which have identified trust (or lack of it) as important in the dynamics of teleworking more generally (e.g. Bailey and Kurland, 2002). Joe and Leora, for example, talked about the importance of displaying trust as a means of encouraging increased productivity, organizational commitment and organizational citizenship behaviours:

I think they give you more. They give you more than 100 percent and there are times once in a while as a manager where I get a call from our folks saying "hey, do you know where so-and-so is? But I know that if necessary that person will also be working at 20 ' clock in the morning to put in extra work if necessary (Joe).

Yes, absolutely, you have to be a manager that believes in trusting your employees - giving them rope; letting them control their lives because it does pay off in the end in terms of what they are willing to do for you, going that extra mile (Leora).

Whitehouse et al. (2002), report a similar finding in their study of teleworking in Australia where they describe how teleworkers would make "extra effort in return for the "privilege" of teleworking"(p. 260). This finding also echoes themes in the contemporary literature on trust, which suggests that it has a positive effect on organizational and individual performance and organizational citizenship behaviours (Frenkel and Orlitzky, 2005). Thus, for example, in a study of a large retain chain in Canada, Deutsch-Salamon and Robinson found that "when employees feel trusted by management, responsibility norms among employees are strengthened, and sales and customer service go up" (2008, p. 599). Focusing on this particular organization, whereas managing office-based employees allows for direct observation, managing flexworkers requires more trust or at least more displayed trust. Several non-managerial interviewees in the larger study reflected this theme, complaining that managers who oppose or resist flexwork are somehow unable or unwilling to 
trust: "I think it's out of my manager's comfort zone" (Lynn). These managers were variously described as "traditional" (Lynn), "old school" (Leora) or as having "hang ups about control" (Niru). It is interesting to note here how managers who are seen as resisting the flexwork initiative are understood, by both their subordinates and their peers, as also being some how outdated or "out of synch" with the contemporary business environment. Conversely, managers who were seen as supporting flexwork were described as "more progressive" (Lynn) and more closely aligned with contemporary management practices and organizational change in a broader sense. Two further points are also worth noting here. First, there is an interesting conflict between discourses that put the "old" against the "new", as if one is inevitably better or more desirable than the other. Second, the connection between interaction and identity is clearly displayed where managers who were perceived as opposing flexwork were ascribed more negative identities.

\section{Discussion}

Located within an interpretive interactionist framework, this paper has suggested that trust, communication and autonomy are key concepts in managing flexworkers. Indeed, these three themes permeated the findings.

Managing flexworkers is "an affair primarily of doing" (Dewey, 1972, p. 329) where the interviewees in this study are constantly trying to balance the need to provide autonomy with the need to maintain communication and cohesion between themselves and their employees as well as between employees - and all in a context of less physical interaction. By reflecting on and adjusting their management style, they adopt more effective management practices in accordance with the changing organizational context and specifically the initiative to encourage more flexworking. They also co-created their management style through interaction with employees by acting on the behaviour of their employees according to the meanings that the respective behaviour has for them. Thus, for example, in order to avoid employees becoming isolated, which they felt would negatively impact on individual, and team performance, they arrange team meetings and other informal get-togethers in the office or somewhere off-site. In this respect their management style is evolving and dynamic rather than static. In other words, they were constantly trying to maintain a balance between "holding on" to employees yet also "letting them go".

The paper also suggests that it is not only the behavioural dynamics between managers and employees that change but also the emotional/relational dynamics. Displaying trust has a positive impact on employees' willingness to engage in organizational citizenship behaviours and their overall productivity. Conversely, managers who were perceived as resisting flexwork were seen as displaying a lack of trust and being somehow "outdated" or "out of touch". This finding accords with interpretive interactionist thought about the connection between self, identity and social interaction. In particular, the paper has suggested that during interaction with others meanings are attributed to a manager's behaviour which are then used to attribute him/her with a particular identity i.e. as being "outdated" or "up to date".

This paper offers a number of implications for management development. First, it signals the need to ensure that managers are aware of the evolving nature of their professional activities where new work practices such as flexworking may require a different managerial style. Second, it highlights the challenge of allowing for autonomy 
but also ensuring appropriate levels of communication, support and control. Ensuring that managers have some awareness of these challenges would allow them to incorporate the requisite and contextually specific management practices to achieve both individual and organizational objectives.

As with most research studies, the study described here has some limitations, which must be acknowledged. Whereas focusing on one particular company allows an in-depth insight and is instructive as a "case study", the extent to which the findings are generalizable to other organizations may be limited. First, they may not be applicable to smaller organizations and given that this study was carried out in Canada they may not be applicable to managers of flexworkers in other countries. Second, the organization at the centre of the study is "technology-based" with extensive expertise to support flexworking. Managers in other industries may have different experiences to those described here. A further limitation of the paper relates to its location within an interpretive interactionist framework, which takes individual action as the primary focus. Yet, the specific value of focusing on individual action is that it has afforded a more "emic" understanding of managing flexworkers which structural perspectives are likely to overlook.

\section{References}

Bailey, D.E. and Kurland, N.B. (2002), "A review of telework research: findings, new directions, and lessons for the study of modern work", Journal of Organizational Behaviour, Vol. 23, pp. 383-400.

Berger, P. (1963), Invitation to Sociology, Doubleday, New York, NY.

Bridgman, T. and Willmott, H. (2006), "Frameworks for understanding organizational change the case of a major ICT outsourcing contract", The Journal of Applied Behavioural Science, Vol. 42 No. 1, pp. 110-26.

Burrell, G. and Morgan, G. (1998), Sociological Paradigms and Organisations, Ashgate Publishing, Aldershot.

Crandall, W.R. and Gao, L. (2005), "An update on telecommuting: review and prospects for emerging issues", SAM Advanced Management Journal, Summer, pp. 30-7.

Denzin, N. (1989), Interpretive Interactionism, Sage, Newbury Park, CA.

Denzin, N. (1991), Image of Postmodern Society: Social Theory and Contemporary Cinema, Sage, Newbury Park, CA.

Denzin, N. (1992), Symbolic Interactionism and Cultural Studies, Blackwell, Cambridge, MA.

Deutsch-Salamon, S. and Robinson, S.L. (2008), "Trust that binds: the impact of collective felt trust on organizational performance", Journal of Applied Psychology, No. 3, pp. 593-601.

Dewey, J.S. (1972), "Mind, experience and behaviour", in Manis, J.G. and Meltzer, B.N. (Eds), Symbolic Interactionism: A Reader in Social Psychology, Allyn \& Bacon, Boston, MA, p. 328.

Frenkel, S. and Orlitzky, M. (2005), "Organizational trustworthiness and workplace labor productivity: testing a new theory", Asia Pacific Journal of Human Resources, Vol. 43, pp. 34-51.

Gainey, T.W. and Clenney, B.F. (2006), "Flextime and telecommuting: examining individual perceptions", Southern Business Review, Vol. 32 No. 1, pp. 13-21.

Harris, L. (2003), "Home-based teleworking and the employment relationship", Personnel Review, Vol. 32 No. 4, pp. $422-37$. 
Kelliher, C. and Anderson, D. (n.d.), "For better or for worse? An analysis of how flexible work practices influence employees' perceptions of job quality", International Journal of Human Resource Management, forthcoming.

King, N. (2004), "Using templates in the thematic analysis of text", in Cassell, C. and Symon, G. (Eds), Essential Guide to Qualitative Methods in Organizational Research, Sage, London, pp. 256-70.

Kvale, S. (1996), Interviews: An Introduction to Qualitative Research Interviewing, Sage, Thousand Oaks, CA

Layder, D. (1994), Understanding Social Theory, Sage, London.

Schweitzer, L. and Duxbury, L. (2006), "Benchmarking the use of telework arrangements in Canada", Canadian Journal of Administrative Sciences, Vol. 23 No. 2, pp. 105-17.

Stone, G.P. (1962), "Appearance and the self", in Rose, R. (Ed.), Human Behavior and Social Processes, Houghton Mifflin, Boston, MA, pp. 86-118.

Tietze, S. (2002), "When 'work' comes 'home': coping strategies of teleworkers and their families", Journal of Business Ethics, Vol. 41 No. 4, pp. 385-97.

Tietze, S. and Musson, G. (2003), "The times and temporalities of home-based telework", Personnel Review, Vol. 32 No. 4, pp. 438-55.

Tremblay, D.G. (2003), "Telework: a new mode of gendered segmentation? Results from a study in Canada", Canadian Journal of Communication, Vol. 28 No. 4, pp. 461-76.

Whitehouse, G.C., Diamond, C. and Lafferty, C. (2002), "Assessing the benefits of telework: Australian case study evidence", New Zealand Journal of Industrial Relations, Vol. 27 No. 3, pp. 257-68.

\begin{abstract}
About the author
Julia Richardson is Associate Professor of Organizational Behaviour at York University, Toronto. Her current areas of research interest are flexible work practices, international mobility and their impact on contemporary careers and management practices. She can be contacted at:
jrichard@yorku.ca
\end{abstract}

